Article

\title{
Green Warehousing: Exploration of Organisational Variables Fostering the Adoption of Energy-Efficient Material Handling Equipment
}

\author{
Tiziana Modica *(D), Sara Perotti and Marco Melacini
}

Department of Management, Economics and Industrial Engineering, Politecnico di Milano, Via Lambruschini 4/B, 20156 Milano, Italy; sara.perotti@polimi.it (S.P.); marco.melacini@polimi.it (M.M.)

* Correspondence: tiziana.modica@polimi.it

Citation: Modica, T.; Perotti, S.; Melacini, M. Green Warehousing: Exploration of Organisational Variables Fostering the Adoption of Energy-Efficient Material Handling Equipment. Sustainability 2021, 13, 13237. https://doi.org/10.3390/ su132313237

Academic Editor: Chi-Ming Lai

Received: 10 September 2021 Accepted: 25 November 2021 Published: 29 November 2021

Publisher's Note: MDPI stays neutral with regard to jurisdictional claims in published maps and institutional affiliations.

Copyright: (c) 2021 by the authors. Licensee MDPI, Basel, Switzerland. This article is an open access article distributed under the terms and conditions of the Creative Commons Attribution (CC BY) license (https:// creativecommons.org/licenses/by/ $4.0 /)$.

\begin{abstract}
The lithium-ion battery (LIB) represents a useful lever for reducing material handling equipment's (MHE) environmental impact. The exploitation of opportunity charging might improve LIB adoption, which is still prevented by the high investment cost. Since opportunity charging is affected by the system organization, the relationship between LIB and organizational variables is a meaningful work direction to reduce warehouses' environmental impact, which is underrepresented by the current literature. The present paper aims at filling this gap by investigating the implications of organisational variables on LIB adoption in warehouses where handling activities are performed with forklift trucks. Based on an in-depth review of the literature and semi-structured interviews, the research presents an input-process-output model linking organisational variables and LIB forklift related costs with an application to a real case. This paper is original as it extends findings from the research fields of production and mobility to the warehouse arena, and it opens room for further research on warehouse sustainability. The paper also offers insights to warehouse managers making decisions about LIB adoption for their electric forklift fleets. This is particularly meaningful to reduce warehouse environmental impact, since MHE power source significantly contributes to greenhouse gases emissions.
\end{abstract}

Keywords: green warehousing; material handling equipment; lithium-ion battery forklift; warehouse organization; input-process-output model

\section{Introduction}

The past 20 years witnessed the significant rise in greenhouse gases (GHG) emissions, with carbon dioxide (CO2) reaching $405.5 \pm 0.1 \mathrm{ppm}$ in 2017 [1]. Many agreements and conventions addressed climate change in their agenda, seeking to reduce the anthropogenic footprint. In this challenging scenario, logistics operations play a key role as they carry significant implications in terms of environmental sustainability [2]. It is estimated that logistics activities generate 5.5\% of the global GHG emissions, with warehouses being among the most impacting, accounting for $11 \%$ of the global GHG emissions derived from logistics processes [3].

Energy consumption related to buildings, such as heating or lighting systems and intra-logistics, including material handling, generate most of the environmental impact of logistics sites [4]. Of these, material handling processes represent a crucial improvement area for the reduction of warehouse emissions [5]. Since handling equipment accounts for one-third of the energy used for material handling, the adoption of eco-efficient forklift trucks could be a valuable solution for minimising energy consumption [6]. According to Facchini et al. [7], electric forklifts outperform other power sources in terms of environmental impact. In this arena, the lithium-ion technology recently raised researchers and practitioners' attention thanks to its high energy efficiency, long-lasting lifespan, and ability to operate over a wide range of temperatures [8]. Despite the significant environmental 
and economic improvements offered during its operating life, the investment cost related to the lithium-ion battery (LIB) still prevents its adoption in warehouses [9]. Optimising the battery charging strategy allows one to diminish the power capacity required, since a smaller and therefore cheaper battery can be selected $[10,11]$. In this regard, the 'opportunity charging' strategy-i.e., a charging strategy that performs fast, sometimes partial charges during the operation phase by the use of fast-chargers-proved to be a good one for reducing LIB size and related costs as it allows the battery to be charged frequently without being removed from the forklift [12]. Since opportunity charging can be performed during the system idle times, its effectiveness in reducing LIB size and related costs is strictly related to the system organisational variables such as working shifts and breaks.

Recent studies explored the effect of opportunity charging on the economic suitability of lithium-ion technology in different fields, such as mobility-focusing on electric buses [12] - production, and warehousing - mostly focusing on Automated Guided Vehicles (AGVs) $[9,11]$. Beside applications in AGVs, the opportunity charging strategy might boost LIB adoption also in warehouses where handling activities are performed with forklift trucks - named as 'labour-intensive' warehouses in the remainder of the paper-which still represent the majority of logistics facilities [3]. Specifically, the focus on labour-intensive warehouses, where the operators' breaks are flexible idle times [13], offer interesting opportunities for investigating the relationship between warehouse organisational variables and the adoption of LIB forklifts.

To date, most of the LIB forklifts related literature belongs to the energy management and the energy systems research areas. Few academic contributions have studied LIB forklifts from a logistics and supply chain management viewpoint. For instance, Carli et al. [5] recently developed an optimal scheduling strategy for electric forklifts in terms of both profit and sustainability. Additionally, Minav et al. [14] proposed a forks speed control method improving forklift energy efficiency. However, to the best of the authors' knowledge, no journal papers specifically addressed the relationship between warehouse organisation and the effectiveness of opportunity charging in reducing LIB related costs, therefore increasing companys' potential willingness to implement such solution.

Based on these premises and the importance that LIB adoption might have in decarbonising warehouse operations [3] this paper aims to explore the relationship between the adoption of LIB forklifts and the related warehouse organisational variables in labourintensive warehouses. Specifically, it studies how organisational variables affect the costs associated with electric forklift LIB. An input-process-output model was developed for this purpose and applied to a real case. A sensitivity analysis was performed to test the impact of specific organisational variables on electric forklift LIB related costs.

The remainder of this paper is organised as follows. Section 2 describes the relevant literature, while Section 3 presents the research questions and illustrates the methodology. Section 4 illustrates the input-process-output model, while Section 5 reports the model application, the sensitivity analysis and the main findings. Section 6 discusses the results highlighting the theoretical and practical contribution of the research. Section 7 reports the conclusions and streams for further developments.

\section{Literature Review}

\subsection{Energy Efficiency in Warehousing: The Role of Material Handling}

Recently, warehouses have increased their energy consumption figures-and consequently their share of supply chain GHG emission-due to the real-time fulfilment requirements which calls for a $24 \mathrm{~h}$ a day running and the growing power needs associated to the extended use of information technology [15]. The longer operating times require a higher-intensity use of material handling equipment (MHE), which has been appointed as one of the main energy consumption areas in warehouses, strongly contributing to the increase in GHG emissions [13]. Material handling systems have been targeted with various initiatives aiming at achieving higher energy efficiency for both labour-intensive warehouses and Automated Storage and Retrieval Systems (AS/RS) [16]. Despite AS/RS in- 
volve most of the energy consumed for material handling [4], labour-intensive warehouses equipped with forklift trucks still represent the majority of logistics buildings [3]. Thus, focusing on forklift trucks energy optimisation could represent a meaningful direction for reducing the GHG emissions of warehousing operations. The GHG emissions generated by forklift trucks depend on the unitary energy consumption and on the time required to complete a process [13]. Facchini et al. [7] highlights three possible strategies to improve these parameters: (i) the optimisation of the forklift routing, (ii) the reduction of movements through ad hoc storage policies, and (iii) the adoption of forklift trucks characterised by lower unitary energy consumption. Regarding the latter strategy, green technology investments in forklift engines can play a role in minimising carbon emissions [17]. In the debate around the best technology for reducing environmental emissions, electric forklifts are preferred, as a general approximation [7]. In this regard, the choice of the electric battery technology represents an important decision in terms of both environmental and economic efficiency [8]. Two technologies are usually called into questions for electrically powered forklifts: lead acid battery (LAB) and LIB. LIB proves a better performance in terms of energy efficiency and operating costs compared to LAB [8]. However, their investment cost is estimated more than four times the average investment cost of LAB [9]. Since the high cost of energy efficient solutions can be a potential barrier to carbon emissions abatement in warehousing [15], recent research on manufacturing has shifted the focus towards exploring new ways to keep LIB investment economically feasible. For instance, Cicconi et al. [9] compares the total cost of ownership of a LAB AGV with a LIB one demonstrating that charging strategies can reduce the battery size and investment cost, making their adoption more economically feasible.

\subsection{Lithium-Ion Batteries (LIB) Adoption and Organisational Implications}

Lithium is attested as one of the most promising technologies for electric batteries on the market, as its characteristics allow manufacturing batteries with low weight and high performances in terms of energy efficiency and speed of the charging process [14]. Despite the significant reduction of energy consumption offered during its operating life, the average cost of a LIB is still an issue for warehouse managers [8]. Optimal battery capacity sizing represents an important lever which might help in recovering the LIB investment $[18,19]$. Studies addressing LIB cost analysis for industrial and warehouse applications highlight different costs associated with these batteries. Among these, investment costs refer to the battery cost mainly, being it considered as the highest burdens of LIB adoption [10]. These increases with the capacity of the battery and therefore with the energy that the battery can provide [12]. The battery might be replaced, since its lifespan-which is bounded by the total number of full charge and discharge cycles that it can experience-might be shorter than the one of the electric machinery powered [9]. The charger cost represents the other investment cost usually associated with LIB; its price varies according to the speed of charge provided to the battery [19]. The operating costs associated with the LIB mainly include the annual energy cost and the maintenance cost. The first depends on the energy consumed by the LIB. which is usually estimated considering both technological factorssuch as the type of machinery hosting the battery [14] —and contextual factors including the operating route performed by the machinery - which depends on the horizontals and vertical path and speeds [19] and it is bounded by the facility layout where the machinery is working [20]-the average workload carried [10], and the temperature of the working environment [8].

Recent studies highlighted the role that charging strategy selection has in fostering the LIB adoption. In particular, authors recognized the opportunity charging strategy as a way to lower LIB related costs [8]. Indeed, when fast and more frequent charges are performed, the required capacity of LIB decreases, and a smaller battery can be chosen, with consequent economic benefits $[9,11]$. Opportunity charging is usually performed during idle times, to minimise the charging downtimes [10]. In this sense, some authors recognise that organisational variables such as the number and the duration of the idle 
times during the working day combined with the opportunity charging could affect the right battery sizing $[12,21,22]$. Indeed, a shorter time available for opportunity charging and a longer time between two consequent charges lead to an increase in the battery capacity needed to perform the operating activities required [12]. Although opportunity charging combined with some organisational variables have started to be acknowledged as a way to foster LIB adoption in warehouses [8], ad hoc studies in this domain are still underrepresented. To date, no authors have analysed how different organisational variables, and, consequently, the different opportunities of charging strategies, affect LIB adoption. Most of the studies on the impact of opportunity charging on LIB costs in logistics applications focused on automated systems and considered the number and the duration of idle time as fixed $[9,11]$. Conversely, in labour-intensive warehouses organisational variables such as the length and the number of the operator's breaks which determine the LIB forklift idle times can be varied according to the needs of the warehouse operators [23]. However, no studies have clearly focused on analysing how these organisational variables can affect the adoption of LIB for electric forklifts, nor the related impact that a change in these variables has on the cost related with electric forklift LIB.

\section{Research Methodology}

While LIB offers many opportunities to improve labour-intensive warehouses' energy efficiency and environmental impact, the related investment costs represent their main barrier to adoption. Nevertheless, the combination of opportunity charging with organisational variables seems a promising strategy to lower the LIB size and related investment cost, thus fostering their adoption. While previous studies proved this relationship in other fields, similar studies in the warehouse literature are underrepresented. Based on the gaps that emerged from the literature review, two research questions were selected to drive the analysis:

RQ1: What organisational variables can affect the costs related to LIB forklifts?

RQ2: What is the impact of organisational variables on the LIB forklift costs?

To address the objectives of this research, a two-phase methodology was adopted (Figure 1). In the first phase, the main organisational variables affecting LIB forklift adoption were investigated, addressing RQ1. In the second phase, the relationship between organisational variables and LIB forklift adoption was studied by developing an inputprocess-output model linking organisational variables and the costs related to the electric forklift LIB. The model was applied to a real case and a sensitivity analysis was eventually performed by varying some specific organisational variables, to assess their impact on the costs related to electric forklift LIB.

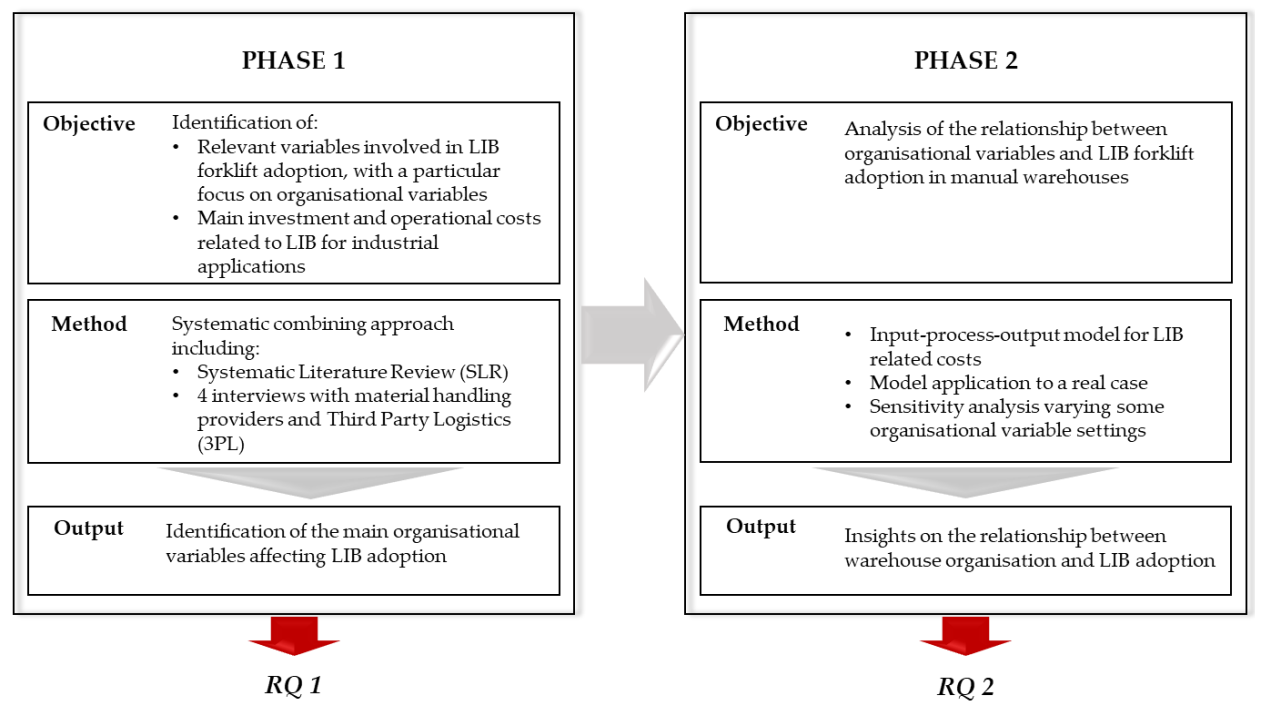

Figure 1. Research methodology. 
In phase 1 , a systematic combining approach was applied. As described by Dubois and Gadde (p. 554), systematic combining is "a process where theoretical framework, empirical fieldwork and case analysis evolve simultaneously" [24]. The process started by reviewing the literature on the topic to identify the relevant costs related to electric forklift LIB and related variables, with a focus on organisational ones. The relevant literature was selected with a systematic search approach. Databases including Scopus, WOS, Science Direct and Google Scholar were investigated by using a combination of keywords such as "warehous*", "logistic*", "forklift" "organisation*", "organiz", , "li-ion", "lithium", "electric", "opportunity charging". The resulting journal papers and conference proceedings discussed (i) energy efficiency in warehouses, (ii) electric forklifts with LIB, (iii) organisational strategies and LIB were selected and carefully analysed. Four semi-structured interviews with company managers were then conducted to test and extend the literature findings by including the industrial viewpoint. The interviews included both material handling providers and third-party logistics (3PL) to cover different perspectives and validate the relevance of the variables emerged from the literature review. The database of the Contract Logistics Observatory at Politecnico di Milano (Italy) helped the selection process. Companies were selected based on their expertise with lithium-ion technology as well as their availability in sharing their experience and being involved in the study. Specifically, the material handling providers interviewed are two European leading companies in the field of LIB forklifts, whereas the 3PLs selected have recently adopted the lithium-ion technology to their electric forklift fleet. Interviewees were supply chain or logistics directors and warehouse managers for 3PLs, and product managers for material handling providers. Confidentiality was guaranteed due to the sensitive nature of the topic, thus neither companies nor individuals can be revealed. The interviewees received semi-structured questionnaires in advance and-due to the COVID-19 emergency-MS Teams interviews were arranged lasting approximately one to two hours. Interviews relied on a focused interview format - in which the interviewer follows a set of predetermined questions_-and remained open-ended to allow the interviewees to express their opinions and experience into certain issues. Secondary data were collected from the company website, company reports and published information to provide background and context for the primary research data gathered from the interviews and perform data triangulation [25]. Three researchers jointly discussed the information emerged from the interviews which confirmed the variables found in the literature. This phase strengthened the understanding about the mechanisms that lead organisational variables affecting the adoption of LIB forklift.

In phase 2, an input-process-output model [26] was developed to study the relationship between organisational variables and the adoption of LIB in the context of the labour-intensive warehouse. In doing so, the costs associated to the electric forklift LIB were assessed, as lower costs may concur to a higher adoption level of such technology [10]. Besides organisational variables, technological and contextual variables were simultaneously considered as model inputs, as they concur to the definition of the electric forklift LIB related costs. A sensitivity analysis was performed to study the impact of different organisational variable settings on the costs associated to the electric forklift LIB.

\section{Model Architecture}

Figure 2 reports the input-process-output model developed to explore the relationship between organisational variables and related forklift LIB costs. 


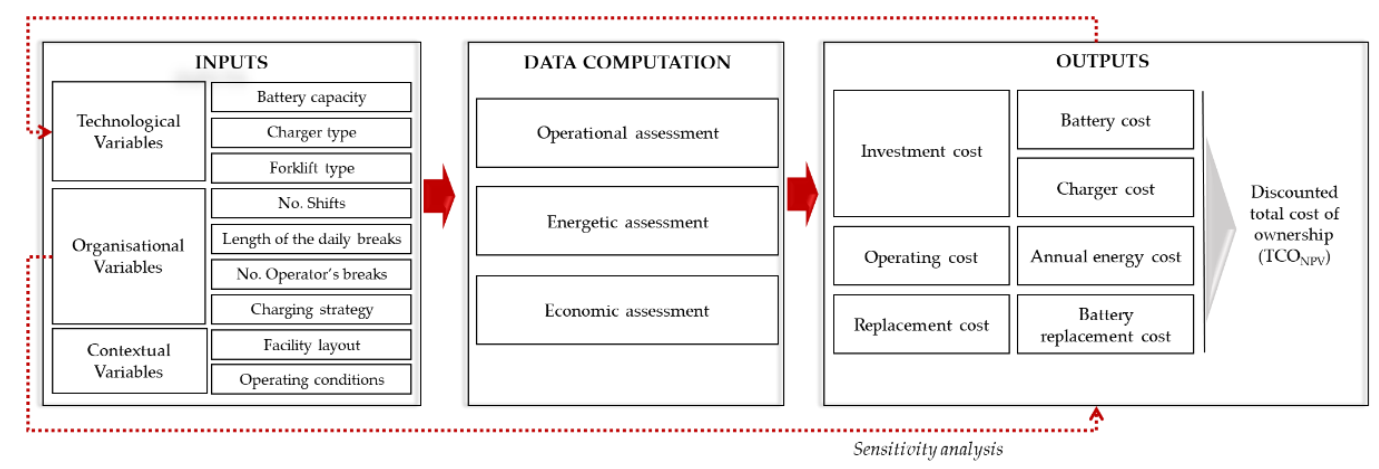

Figure 2. Model architecture.

Three different types of inputs were considered namely technological, organisational, and contextual variables. They consist of the main relevant variables affecting the costs related to the electric forklift LIB, as emerged from both the literature review and the interviews (Table 1). Technological variables include:

- Battery capacity is the capacity of the battery expressed in kWh; it affects the total available energy provided by the battery;

- $\quad$ Charger type is the type of charger used to perform the battery charging (e.g., fast charger);

- Forklift type is the type of LIB forklift used for handling operations (e.g., picking truck, counterbalance forklift truck, straddle reach truck).

Organisational variables include:

- No. shifts which represents the number of operating shifts related to the labourintensive warehouse scheduling. It affects the forklift total operating time;

- Length of the daily breaks which includes the duration of each operator downtimes and it affects the total forklift idle time;

- No. operator breaks which includes the frequency of the operator downtimes performed during each shift and it affects the total forklift idle time;

- Charging strategy which consists in selecting how to perform the battery charging (e.g., opportunity charging, battery swapping).

Contextual variables include:

- Facility layout which comprises the size, shape and space arrangement (layout) of the labour-intensive warehouse where the LIB forklift operates;

- Operating conditions which comprises of the warehouse temperature according to the requirements of the stocked goods, the average weight of goods to be loaded, and the maximum operating height reached by the LIB forklift.

Table 1. Main input of the model and related references in the literature.

\begin{tabular}{ccc}
\hline Variable Type & Variable & References \\
\hline \multirow{3}{*}{ Technological } & Battery capacity & {$[9,10,12]$} \\
& Charger type & {$[9-12]$} \\
& Forklift type & {$[9,10,20]$} \\
\hline \multirow{3}{*}{ Organisational } & No. shifts & {$[10]$} \\
& Length of the daily breaks & {$[5,8]$} \\
& No. operator's breaks & {$[5,8]$} \\
& Charging strategy & {$[8,9,12]$} \\
\hline Contextual & Facility layout & {$[5,10,11]$} \\
& Operating conditions & {$[8-11]$} \\
\hline
\end{tabular}

The process leading to the output identification, named as data computation, comprises three steps. The first consists of collecting all the input variables according to the 
system studied, defining the scenario of analysis. The average duration and the average energy required to perform warehouse operations is estimated according to the input variables (i.e., operational assessment). The second step involves the energetic assessment consisting in an evaluation of the LIB State of Charge (SoC), intended as the percentage of residual energy of the LIB during its operating conditions with respect to the overall energy provided by the fully charged battery. The energetic assessment checks whether the selected battery capacity can supply the energy required for the entire duration of warehouse operations. The final step includes the economic assessment of the examined scenario.

A total cost of ownership (TCO) approach defines the model outputs, assessing all the costs associated with the electric forklift LIB throughout the forklift operating life. As suggested by literature, the TCO computation considers the investment cost $\left(C_{C A P}\right)$, the operating cost $\left(C_{O P E}\right)$, and the replacement cost $\left(C_{R E P}\right)$, related to the electric forklift LIB. The investment cost $\left(C_{C A P}\right)$ includes:

- $\quad$ Battery cost (EUR): the purchasing cost of the battery including the number of cells and the Battery Management System;

- Charger cost (EUR): the cost related to the equipment used for the battery charging; it is affected by the power value selected for charging.

Other forklift costs were neglected as they were considered not differential. The operating cost $\left(C_{O P E}\right)$, includes the annual energy cost (EUR/year) namely the cost related to the energy consumed for charging the battery, as shown in Equation (1).

Annual energy cost $(€ /$ year $)=$ Yearly power $(\mathrm{kWh} /$ year $) *$ Unit energy cost $(€ / \mathrm{kWh})$

The yearly power (kWh/year) required by the electric battery of the forklift is computed considering the total number of working days per year, the number of shifts per day and the energy consumption for each shift (kWh/shift). Although other contributions may suggest also considering the battery maintenance cost [12], this model does not include them, since the small size of the batteries analysed makes them negligible [9]. Finally, the replacement cost $\left(C_{R E P}\right)$ includes the battery replacement cost (EUR) related to the battery substitution at the end of its lifespan. In our work we assume that: (i) the electric forklift allows to remove and replace batteries, and (ii) the lifespan of the battery is shorter than the average operating life of the electric forklift.

Given the different nature of the costs considered, a net present value (NPV) evaluation was then performed on the TCO incurred along the electric forklift operating life. Equation (2) represents the discounted TCO $\left(T C O_{N P V}\right)$ :

$$
T C O_{N P V}=C_{C A P}+\sum_{t=1}^{n} \frac{C_{O P E}(t)+C_{R E P}(t)}{(1+k)^{t}},
$$

where $t$ is the year of ownership of the LIB forklift, $n$ is the total number of years of ownership of the LIB forklift, and $k$ is the discount rate. The following assumptions were considered to compute the $T C \mathrm{O}_{N P V}$ for the LIB forklifts:

- $\quad$ Electric forklift operating life is assumed equal to 10 years;

- $\quad$ The expected lifespan of the LIB is assumed equal to 3200 complete charging and discharging cycles, in line with Material Handling Providers' guidelines;

- The electric forklift operates continuously during the working shift;

- The workload of the electric forklift is evenly distributed within the working shift;

- The charging and discharging profile of the LIB is approximated to a linear function, according to both interviews and the assumptions already adopted in the literature [19].

- $\quad$ The discount rate is assumed equal to $5 \%$ per year. 


\section{Model Application}

This section describes the application of the model, starting from the description of the base case (Scenario A) and those considered within the sensitivity analysis (Scenario B and $\mathrm{C}$ ). The results of the application are then presented.

The model was applied to a labour-intensive warehouse located in the North of Italy, with a total floor space equal to 33,000 sqm and a storage capacity of 34,000 full pallet loads. The warehouse is fully equipped with single-deep selective pallet racks and served by a fleet of 76 straddle reach LIB forklift trucks. The warehouse operates 250 days per year. A working day is organised into two shifts of $8 \mathrm{~h}$ each. The warehouse management has recently decided to introduce the LIB forklift technology combined with the opportunity charging strategy to improve warehouse energy efficiency and to remove the battery charging room, thus increasing the area available for storage. Currently, the LIB forklift is charged during two long operator's breaks $(90 \mathrm{~min}$ each) that are scheduled in the middle of each shift. Table 2 shows the data used for the model application in this scenario, referred to as Scenario A (base case), and in the other two scenarios used for the sensitivity analysis. These include the input variables, the unitary investment costs and operating cost considered to compute the $T C O_{N P V}$ analysis.

Table 2. Sensitivity analysis: examined scenarios and related data.

\begin{tabular}{|c|c|c|c|}
\hline & & Scenario & \\
\hline Data & A (Base Case) & B & $\mathrm{C}$ \\
\hline Battery capacity & $28.8 \mathrm{kWh}$ & $21.6 \mathrm{kWh}$ & $19.2 \mathrm{kWh}$ \\
\hline Charger type & Fast charger (300 A) & Fast charger (300 A) & Fast charger (300 A) \\
\hline Forklift type & $\begin{array}{l}\text { Straddle reach LIB } \\
\text { forklift truck }\end{array}$ & $\begin{array}{l}\text { Straddle reach LIB } \\
\text { forklift truck }\end{array}$ & $\begin{array}{l}\text { Straddle reach LIB } \\
\text { forklift truck }\end{array}$ \\
\hline No. shifts & 2 shifts / day & 2 shifts/day & 2 shifts/day \\
\hline Length of the daily breaks & $90 \mathrm{~min}$ & $45 \mathrm{~min}$ & $15 \mathrm{~min}$ \\
\hline No. operator's breaks & 1 break/shift & 2 breaks/shift & 6 breaks/shift \\
\hline Charging strategy & Opportunity charging & Opportunity charging & Opportunity charging \\
\hline Operating conditions & $\begin{array}{l}\text { Temperature: } 20^{\circ} \mathrm{C} \\
\text { Avg loaded weight: } \\
\text { 1800-2000 kg } \\
\text { Max operating } \\
\text { height: } 12 \mathrm{~m}\end{array}$ & $\begin{array}{l}\text { Temperature: } 20^{\circ} \mathrm{C} \\
\text { Avg loaded weight: } \\
1800-2000 \mathrm{~kg} \\
\text { Max operating } \\
\text { height: } 12 \mathrm{~m}\end{array}$ & $\begin{array}{l}\text { Temperature: } 20{ }^{\circ} \mathrm{C} \\
\text { Avg loaded weight: } \\
\text { 1800-2000 kg } \\
\text { Max operating } \\
\text { height: } 12 \mathrm{~m}\end{array}$ \\
\hline LIB cost & $19,250 €$ & $15,125 €$ & $13,750 €$ \\
\hline Fast charger cost & $2313 €$ & $2313 €$ & $2313 €$ \\
\hline Energy cost & $0.15 € / \mathrm{kWh}$ & $0.15 € / \mathrm{kWh}$ & $0.15 € / \mathrm{kWh}$ \\
\hline
\end{tabular}

According to the input variables, the operational assessment of Scenario A (base case) was performed. The average duration of warehouse operations, which consist mainly in storage and retrieval activities of full pallet loads, was estimated equal to $2.4 \mathrm{~min}$ for a single command cycle. The average energy required to perform the single command cycle was computed considering the average hourly power absorbed during the working activities and the average duration of the single command cycle, as shown in Equation (3). The hourly power absorbed is affected by the forklift type, the facility layout, and the operating conditions considered, and was estimated equal to $5.50 \mathrm{~kW}$. Therefore, the average energy consumption associated with each single command cycle results equal to $0.22 \mathrm{kWh}$.

Avg energy consumption $(\mathrm{kWh})=$ Discharging hourly power $(\mathrm{kW}) *$ Cycle time $(\mathrm{h})$, (3) 
The average energy recharge was computed considering the average hourly power provided by the charger and the charging time, as shown in Equation (4). The hourly power provided by the charger is affected by the charger type used, and was estimated to be equal to $17.05 \mathrm{~kW}$.

Avg energy recharge $(\mathrm{kWh})=$ Charging hourly power $(\mathrm{kW}) *$ Charging time $(\mathrm{h})$,

Moving from the operational assessment, the energetic assessment was performed, to check whether the battery set for Scenario A (base case) is able to supply the energy required for the entire duration of the working day. For this purpose, the battery SoC was investigated, as shown in Figure 3. The vertical axis of the chart refers to the current value of the battery SoC; being the SoC represented as the percentage level of charge of an electric battery referred to its capacity, it ranges between $100 \%$ (fully charged) and $0 \%$ (empty). To guarantee the working continuity, the minimum acceptable battery SoC has been set to $2 \%$ [19]. The horizontal axis of the graph expresses the daily operating time of the electric forklift, which must cover two shifts of $8 \mathrm{~h}$ each. As emerged the graph, the two long operator's breaks allow to fully charge the battery during the working shifts. The warehouse non-operating time, i.e., between 22:00 and 6:00, allows charging the selected battery completely.

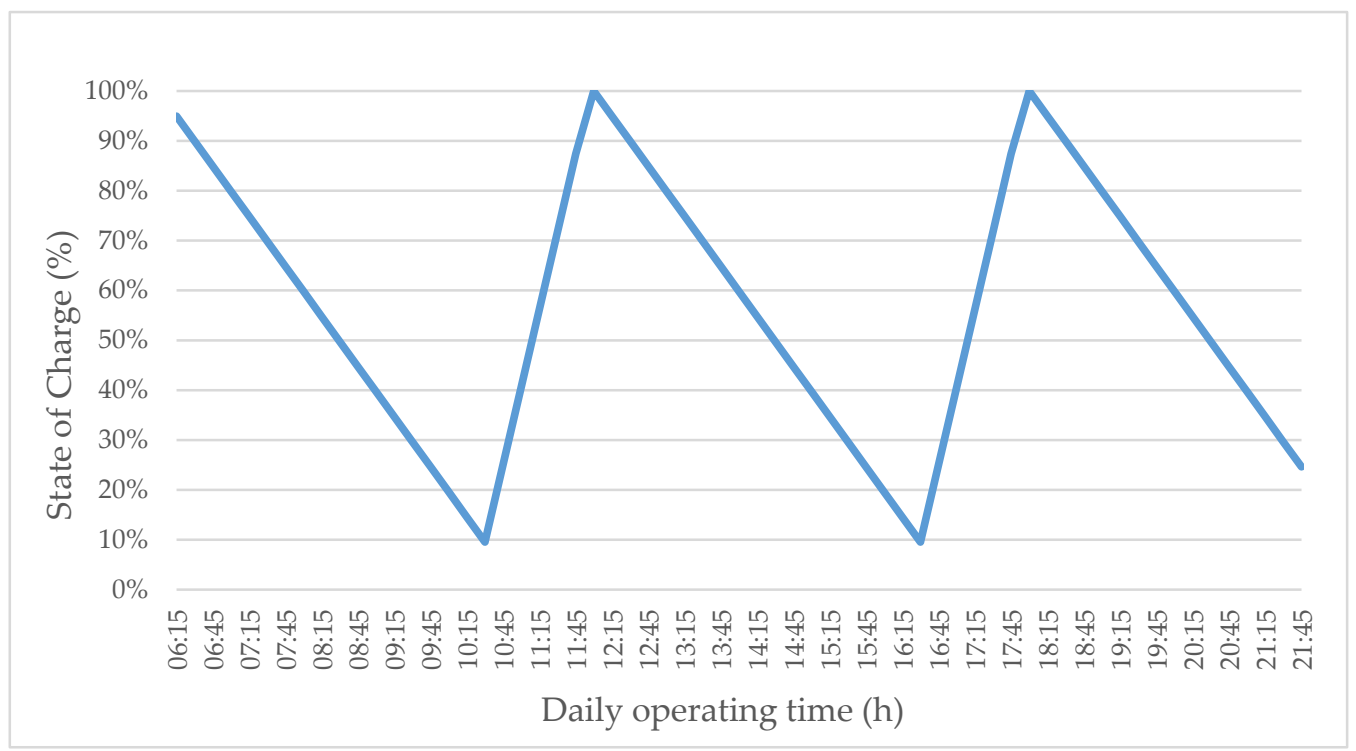

Figure 3. State of charge (SoC) profile for Scenario A (Base case).

Finally, the economic assessment was performed, leading to a $T C O_{N P V}$ associated to Scenario A (base case) of 65,500 EUR, under the assumptions made. The results of the scenario in terms of energy and cost assessment will be further discussed in the following paragraph, together with the results of the sensitivity analysis.

\section{Sensitivity Analysis}

A sensitivity analysis was performed on the organisational variables "No. operator's breaks" and "Length of the daily breaks" to understand how they may affect the investment and operating costs associated to the LIB forklift operating life. For this purpose, two new scenarios, i.e., Scenario B and Scenario C, were defined. In Scenario B, two operator's breaks were assumed for each shift, each lasting $45 \mathrm{~min}$. In Scenario $C$ the number of operator's breaks was considered equal to six breaks per shift, each lasting $15 \mathrm{~min}$, similarly to the break schemes already tested in the operations literature [27]. The new break schemes were designed considering the hypotheses that shorter and more frequent breaks are preferred with respect to longer operating times followed by fewer long breaks [28]. 
The changes in the selected variables were made by keeping constant the overall length of the operator's breaks per shift, i.e., $90 \mathrm{~min} / \mathrm{shift}$ for all scenarios. Table 2 reports the inputs used to perform the sensitivity analysis on the $T C O_{N P V}$. The results obtained by applying the model to the previously defined scenarios are discussed here in terms of operating assessment, energetic assessment—by studying the battery SoC—and economic assessment, by analysing the $T C O_{N P V}$. The operating assessment of Scenario B and Scenario C show the same results of Scenario A (base case), being equal all the input variables affecting (i) the cycle time (i.e., forklift type, facility layout), (ii) the hourly power absorbed (i.e., forklift type, facility layout, operating conditions), and (iii) the hourly power provided during the charging (i.e., charger type).

With the energetic assessment the $\mathrm{SoC}$ for the new scenarios, i.e., Scenario $\mathrm{B}$ and Scenario C, were analysed and the input variable "Battery capacity" — as well as the related battery investment cost-was adjusted in order to have the minimum battery capacity required to cover the overall duration of the operating activities and to guarantee the working continuity (see Table 2). Figure 4 illustrates the charging and discharging profile for the LIB in the three scenarios and shows the combined effect that opportunity charging and organisational variables have on the LIB energetic profile. Since the SoC is represented as a \% of the total charging, the slope of the three curves is different, as the scenarios have batteries with different capacity. Opportunity charging allows recharging the battery during operator breaks, thus increasing the SoC during the warehouse operating time (from 6:00 to 22:00). In Scenario A (base case), the two long operator breaks (90 min each) allow to completely charge the LIB, while in Scenario B the four shorter operator breaks (45 min each) allow restoring the battery SoC between the $70 \%$ and $100 \%$. Finally, the numerous shorter operator breaks (15 min each) considered in Scenario C determine a substantial reduction of the SoC during the operating time, being assessed between $9 \%$ and $34 \%$ from 18:00 until the end of the operating time. When the capacity of the battery decreases, less time is needed for charging and discharging procedures. Therefore, the number of charge and discharge cycles increases together with the increase in the number of breaks, thus lowering the lifespan of the battery for Scenario $C$ with respect to Scenario A (base case). In all scenarios, the warehouse non-operating time, i.e., between 22:00 and 6:00, allows charging all the selected batteries completely.

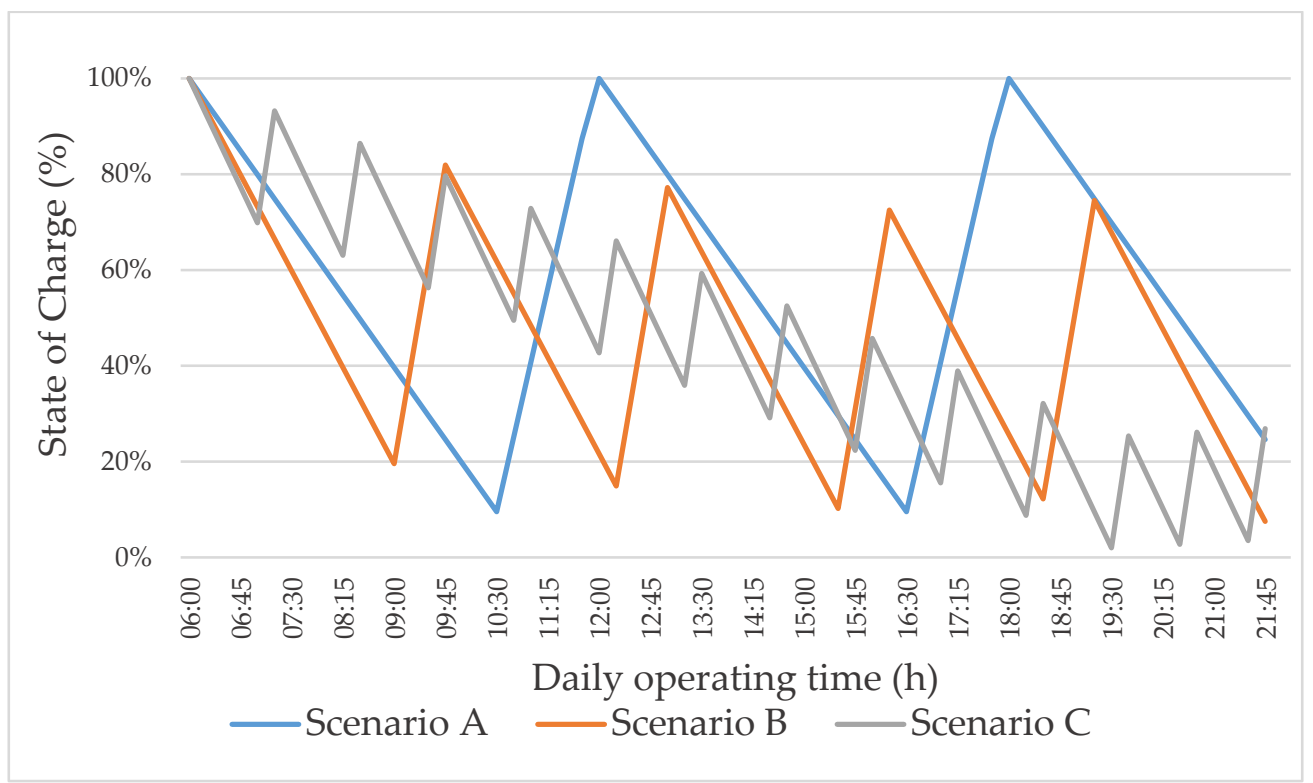

Figure 4. State of charge (SoC) profile for the scenarios analysed.

Figure 5 shows the $T C O_{N P V}$ for the analysed scenarios. Here, the main differences are given by the battery investment cost and the battery replacement cost. Scenario B and C 
have a lower investment cost at year 1 than Scenario A (base case) since the opportunity charging strategy combined with shorter and more frequent operator breaks allows decreasing the size of the LIB, thus lowering the initial battery investment cost. On the contrary, Scenario B and Scenario $C$ have a higher battery replacement cost than Scenario A. This is explained by the decrease in the battery lifespan caused by the more frequent charges performed during the day; the smaller the battery capacity, the higher the number of complete charge and discharge cycles experienced by the battery. As shown in Figure 5, the increase in replacement costs might overcome the savings brought by the reduction of the LIB capacity. At the end of the ten years, the $T C \mathrm{O}_{N P V}$ of the Scenario $\mathrm{C}$, which has a lower battery investment cost, is not the lowest, thus revealing that exceeding in the use of opportunity charging so to minimise the battery size might not be economically convenient. This result is explained by the effect of the battery replacement cost. Being charged more frequently, the smallest battery of Scenario $C$ has to be replaced more frequently. The annual energy cost does not vary among the different scenarios, since the variables affecting energy consumption (forklift type, number of shifts, operating conditions), and the variables affecting energy recharge (overall duration of the operator breaks, charger type) remain the same for the three scenarios, as explained in the operational assessment.

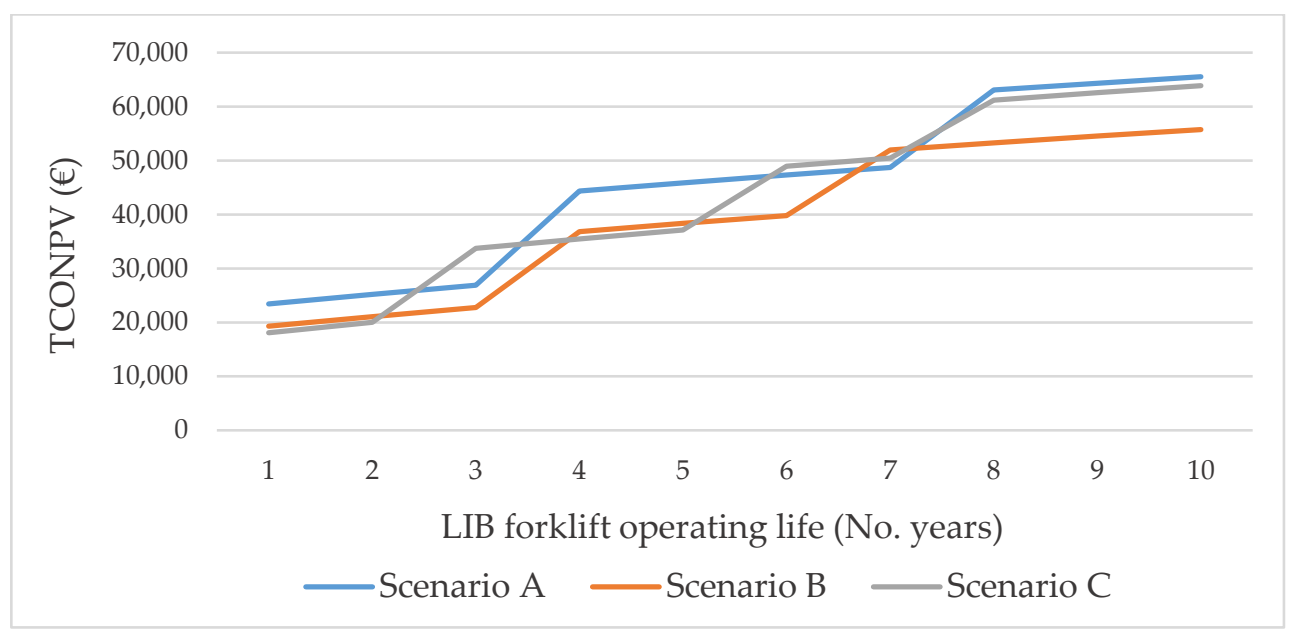

Figure 5. $\mathrm{TCO}_{\mathrm{NPV}}$ for the scenarios analysed.

\section{Discussion}

The length of the daily breaks, the number of operator's breaks, the charging strategy, and the number of shifts appeared to be the main organisational variables affecting the adoption of LIB forklifts in labour-intensive warehouses, as emerged by the analysis conducted. The importance of the organisational variable "charging strategy" has been confirmed for LIB adoption also in the context of labour-intensive warehouses, strengthening the findings of other industrial contexts $[9,11,12,22]$. The other organisational variables identified (i.e., number of shifts, the length of the daily breaks, the number of operator's breaks) represent ad hoc leverages that can be exploited together with opportunity charging to foster LIB adoption in labour-intensive warehouses.

The application of the input-process-output model to the real case proved that the use of opportunity charging increases the importance of other organisational variables (e.g., the number of operator's breaks and the length of the daily breaks) in determining the right LIB sizing and in affecting the costs related with the LIB forklift. In this regard, the sensitivity analysis allowed testing the impact that the organisational variables "Length of the daily breaks" and "No. operator's breaks" have on the costs related with the electric forklift LIB. Two main considerations can be drawn from the application of the input-process-output model to the three scenarios (i.e., Scenario A (base case), Scenario B, Scenario C) set for the sensitivity analysis: 
- By increasing the number of operator's breaks and lowering the length of the daily breaks, a LIB with a smaller capacity is needed. Therefore, a lower battery investment cost is expected;

- By lowering the number of operator's breaks and increasing the length of the daily breaks, the LIB is exposed to less complete charge and discharge cycles. Therefore, the battery needs to be replaced less frequently, and battery replacement cost decreases.

These findings suggest that it is possible to set organisational variables such as the number and the length of operator breaks to decrease the costs related to the electric forklift LIB, fostering the adoption of this technology for labour-intensive warehouses. Last, the introduction of LIB forklifts in labour-intensive warehouses, combined with the opportunity charging strategy, allows optimising human operator's breaks, turning them from ordinary downtimes to important leverages for the system design.

\subsection{Implications for Theory}

The main novelty of the study consists in analysing the effect that organisational variables have in fostering the LIB adoption in labour-intensive warehouses. This is done by studying how these variables affect the costs related to the electric forklift LIB. The study builds upon extant literature findings and extend them to a new research field (i.e., green warehousing); it also contributes to green warehousing literature by offering new directions of analysis. Indeed, by providing an exploratory study about the relationship between the adoption of LIB and labour-intensive warehouse organisational variables this research addresses substantial research gaps and paves the way for future investigations. The contribution of this study is three-fold.

First, it studies how the opportunity charging affects the adoption of LIB electric forklift in labour-intensive warehouses, extending the findings of similar studies carried on in the fields of production $[9,11]$ and electric mobility $[12,22]$. The research highlights the technological, organisational, and contextual input variables and the costs related to the adoption of LIB in labour-intensive warehouses; these findings are supported by the literature and interviews findings, and summarized in the proposed input-processoutput model.

Second, this study contributes to the green warehousing literature by deepening the study on the relationship between organisational variables and LIB adoption. While previous research has focused the attention on opportunity charging as the main variable fostering LIB adoption [8], this study investigates through the sensitivity analysis the role that organisational variables combined with opportunity charging have in optimizing LIB size. Moreover, it assesses the impact that changes in the organisational variables have on the costs related to electric forklift LIB. In this sense, the study proves the relevance of organisational variables in fostering the adoption of LIB, contributing therefore to raise interest in this research area.

Third, this study brings further considerations in the field of work balancing and organisation within labour-intensive warehouse, as it suggests a relationship between warehouse organisational variables (i.e., number and the length of the operator's breaks) and the type of power source selected for the MHE (i.e., LIB). This relationship can be taken into account for the work-rest scheduling activities, alongside with the fatigue-productivity trade-off currently investigated in this research area $[23,28,29]$.

\subsection{Implications for Practice}

The research offers valuable considerations that might help practitioners dealing with green warehousing in labour-intensive warehouse management.

First, the research clarifies the relevant technological, organisational, and contextual variables affecting the electric forklift LIB related costs. Starting from these variables, the input-process-output model allows to compute the investment, operating and replacement costs associated with the LIB forklift, thus supporting companies in the decision to adopt LIB for their electric forklift fleets. The developed model helps supporting the evi- 
dence about the environmental suitability provided by LIB forklift [30] with an assessment about the economic feasibility of the LIB investment, thus increasing the awareness about this technology and promoting its adoption.

Second, the sensitivity analysis highlights the importance of organisational variables in determining the right LIB size. The case performed shows that the number and the length of the operator's breaks affect both the investment and the replacement costs of the LIB, providing practitioners with new insights about the trade-off involved in the selection of the battery size, and offering a tool to assess this trade-off.

The study suggests that there is a bi-directional relationship between the type of power source selected for the MHE and the warehouse design and management. Therefore, practitioners might take into account both the MHE power source and the organisation of their warehouse during the design phase having in mind that downtimes might turn into effective leverage to improve the warehouse sustainability and performance.

\section{Conclusions}

This paper contributes to warehouse environmental performance by studying energyefficient MHE adoption. In doing so, it explores the relationship between the organisation of labour-intensive warehouses and the adoption of LIB forklift by first defining the main variables (i.e., technological, organisational, contextual) affecting the introduction of LIB and then identifying the impact of organisational variables on LIB adoption. By developing an input-process-output model and applying it to a real case, the study showed the impact of the identified variables on the costs related to the electric forklift LIB (i.e., investment costs, operational costs, replacement costs). A sensitivity analysis was performed to explored the relationship between organisational variables and LIB forklift related costs. Findings proved that increasing the number of operator breaks and decreasing their length, a smaller battery is needed to cover the entire working day can reduce the battery investment cost. Nevertheless, short and highly fragmented operator's breaks require a higher battery replacement cost, which might offset the savings brought by the reduction in the battery investment costs.

The results of this study contribute to the literature in the green warehouse research arena as it addresses an issue (energy-efficient MHE adoption combined with organisational aspects) which is still largely uncovered and deserves substantial attention. It also offers numerous implications for managers in the field of logistics and warehousing, as discussed in the previous section.

The research presents some limitations, and interesting streams for future research can be highlighted. First, given the purpose of the study, the average charge and discharge values have been defined as pre-set inputs. Future research could analyse the battery SoC through simulation, thus increasing the accuracy of the battery capacity estimation. Moreover, further studies could focus on the role of human operators, to include the effect of driver's behaviour on energy consumption. Second, to allow the generalisability of results, an extended study is recommended by examining additional scenarios and further industrial cases including, for instance, warehouses with a different layout or operating conditions. Third, given the small battery capacity, the study did not consider any maintenance or disposal cost. In the future, these costs might be included in the model, to refine the analysis with further elements, thus allowing for both lifecycle assessment (LCA) analyses and the investigation of the environmental impact associated to battery disposal. Circular economy practices for LIB might be introduced when evaluating battery disposal costs [31]. Finally, further studies could explore synergies among LIB and other energy-efficient warehousing solutions. Indeed, leveraging on organisational variables such as opportunity charging can increase the percentage of battery charging cycles performed during the day. This represents an opportunity to exploit green energy sources in warehouses such as photovoltaic panels to perform these charges. 
Author Contributions: Conceptualization, T.M., S.P. and M.M.; methodology, T.M. and S.P.; validation, T.M., S.P. and M.M.; formal analysis, T.M.; investigation, T.M.; resources, M.M.; data curation, T.M.; writing-original draft preparation, T.M. and S.P.; writing—review and editing, T.M., S.P. and M.M.; visualization, T.M.; supervision, S.P. and M.M.; project administration, M.M.; All authors have read and agreed to the published version of the manuscript.

Funding: This research received no external funding.

Institutional Review Board Statement: Not applicable.

Informed Consent Statement: Not applicable.

Conflicts of Interest: The authors declare no conflict of interest.

\section{References}

1. WMO. GREENHOUSE GAS BULLETIN The State of Greenhouse Gases in the Atmosphere Based on Global Observations through 2017. pp. 1-8. Available online: https:/ / library.wmo.int/doc_num.php?explnum_id=5455 (accessed on 16 January 2021).

2. Evangelista, P.; Santoro, L.; Thomas, A. Environmental sustainability in third-party logistics service providers: A systematic literature review from 2000-2016. Sustainability 2018, 8, 1627. [CrossRef]

3. Ries, J.M.; Grosse, E.H.; Fichtinger, J. Environmental impact of warehousing: A scenario analysis for the United States. Int. J. Prod. Res. 2017, 55, 6485-6499. [CrossRef]

4. Freis, J.; Vohlidka, P.; Günthner, W.A. Low-Carbon warehousing: Examining impacts of building and intra-logistics design options on energy demand and the CO2 emissions of logistics centers. Sustainability 2016, 8, 448. [CrossRef]

5. Carli, R.; Dotoli, M.; Digiesi, S.; Facchini, F.; Mossa, G. Sustainable scheduling of material handling activities in labor-intensive warehouses: A decision and control model. Sustainability 2020, 12, 3111. [CrossRef]

6. Evangelista, P.; Colicchia, C.; Creazza, A. Is environmental sustainability a strategic priority for logistics service providers? J. Environ. Manag. 2017, 198, 353-362. [CrossRef]

7. Facchini, F.; Mummolo, G.; Mossa, G.; Digiesi, S.; Boenzi, F.; Verriello, R. Minimizing the carbon footprint of material handling equipment: Comparison of electric and LPG forklifts. J. Ind. Eng. Manag. 2016, 9, 1035-1046. [CrossRef]

8. Alshaebi, A.; Dauod, H.; Weiss, J.; Yoon, S.W. Evaluation of different forklift battery systems using statistical analysis and discrete event simulation. In Proceedings of the 2017 Industrial and Systems Engineering Conference, Pittsburgh, PA, USA, 20-23 May 2017; pp. 1637-1642.

9. Cicconi, P.; Postacchini, L.; Pallotta, E.; Monteriù, A.; Prist, M.; Bevilacqua, M.; Germani, M. A life cycle costing of compacted lithium titanium oxide batteries for industrial applications. J. Power Sources 2019, 436, 226837. [CrossRef]

10. Kabir, Q.S.; Suzuki, Y. Increasing manufacturing flexibility through battery management of automated guided vehicles. Comput. Ind. Eng. 2018, 117, 225-236. [CrossRef]

11. Zou, B.; Xu, X.; Gong, Y.; De Koster, R. Evaluating battery charging and swapping strategies in a robotic mobile fulfillment system. Eur. J. Oper. Res. 2018, 267, 733-753. [CrossRef]

12. Lajunen, A. Lifecycle costs and charging requirements of electric buses with different charging methods. J. Clean. Prod. 2018, 172, 56-67. [CrossRef]

13. Bartolini, M.; Bottani, E.; Grosse, E.H. Green warehousing: Systematic literature review and bibliometric analysis. J. Clean. Prod. 2019, 226, 242-258. [CrossRef]

14. Minav, T.A.; Murashko, K.; Laurila, L.; Pyrhönen, J. Forklift with a lithium-titanate battery during a lifting/lowering cycle: Analysis of the recuperation capability. Autom. Constr. 2013, 35, 275-284. [CrossRef]

15. Goh, S.H. Barriers to low-carbon warehousing and the link to carbon abatement: A case from emerging Asia. Int. J. Phys. Distrib. Logist. Manag. 2019, 49, 679-704. [CrossRef]

16. Tappia, E.; Marchet, G.; Melacini, M.; Perotti, S. Incorporating the environmental dimension in the assessment of automated warehouses. Prod. Plan. Control 2015, 26, 824-838. [CrossRef]

17. Chen, X.; Wang, X.; Kumar, V.; Kumar, N. Low carbon warehouse management under cap-and-trade policy. J. Clean. Prod. 2016, 139, 894-904. [CrossRef]

18. Ostadi, A.; Kazerani, M. Optimal sizing of the battery unit in a plug-in electric vehicle. IEEE Trans. Veh. Technol. 2014, 63, 3077-3084. [CrossRef]

19. Renquist, J.V.; Dickman, B.; Bradley, T.H. Economic comparison of fuel cell powered forklifts to battery powered forklifts. Int. J. Hydrogen Energy 2012, 37, 12054-12059. [CrossRef]

20. Vivaldini, K.C.T.; Oliveira, M.M.; Galdames, J.P.; Santos, J.A.; Magalhaes, D.V.; Becker, M. Battery charge state estimate for a robotic forklift routing system. In Proceedings of the IEEE International Conference on Industrial Technology, Cape Town, South Africa, 25-28 February 2013; pp. 1222-1227. [CrossRef]

21. Vilppo, O.; Markkula, J. Feasibility of electric buses in public transport. World Electr. Veh. J. 2015, 7, 357-365. [CrossRef]

22. Sweda, T.M.; Dolinskaya, I.S.; Klabjan, D. Adaptive routing and recharging policies for electric vehicles. Transp. Sci. 2017, 51, 1326-1348. [CrossRef] 
23. Zhao, X.; Liu, N.; Zhao, S.; Wu, J.; Zhang, K.; Zhang, R. Research on the Work-rest Scheduling in the Manual Order Picking Systems to Consider Human Factors. J. Syst. Sci. Syst. Eng. 2019, 28, 344-355. [CrossRef]

24. Dubois, A.; Gadde, L.E. Systematic combining: An abductive approach to case research. J. Bus. Res. 2002, 55, 553-560. [CrossRef]

25. Perotti, S.; Zorzini, M.; Cagno, E.; Micheli, G.J.L. Green supply chain practices and company performance: The case of 3PLs in Italy. Int. J. Phys. Distrib. Logist. Manag. 2012, 42, 640-672. [CrossRef]

26. Lv, L.; Deng, Z.; Meng, H.; Liu, T.; Wan, L. A multi-objective decision-making method for machining process plan and an application. J. Clean. Prod. 2020, 260, 121072. [CrossRef]

27. Lodree, E.J.; Geiger, C.D.; Jiang, X. Taxonomy for integrating scheduling theory and human factors: Review and research opportunities. Int. J. Ind. Ergon. 2009, 39, 39-51. [CrossRef]

28. Kopardekar, P.; Mital, A. The effect of different work-rest schedules on fatigue and performance of a simulated directory assistance operator's task. Ergonomics 1994, 37, 1697-1707. [CrossRef]

29. Calzavara, M.; Persona, A.; Sgarbossa, F.; Visentin, V. A model for rest allowance estimation to improve tasks assignment to operators. Int. J. Prod. Res. 2019, 57, 948-962. [CrossRef]

30. Scrosati, B.; Garche, J. Lithium batteries: Status, prospects and future. J. Power Sources 2010, 195, 2419-2430. [CrossRef]

31. Mossali, E.; Picone, N.; Gentilini, L.; Rodrìguez, O.; Pérez, J.M.; Colledani, M. Lithium-ion batteries towards circular economy: A literature review of opportunities and issues of recycling treatments. J. Environ. Manag. 2020, 264, 110500. [CrossRef] 